\title{
Study on the Damage Evolution Process and Fractal of Quartz- Filled Shale under Thermal-Mechanical Coupling
}

\author{
Zhonghu Wu ${ }^{1 D},{ }^{1,2,3}$ Huailei Song ${ }^{D},{ }^{1}$ Liping $\mathrm{Li}^{2,3}$ Zongqing Zhou, ${ }^{2}$ Yujun Zuo ${ }^{\mathrm{D}},{ }^{4}$ \\ Wenjibin Sun, ${ }^{4}$ Hao Liu, ${ }^{4}$ and Yili Lou ${ }^{1}$ \\ ${ }^{1}$ College of Civil Engineering, Guizhou University, Guiyang 550025, China \\ ${ }^{2}$ School of Qilu Transportation, Shandong University, Jinan 250002, China \\ ${ }^{3}$ Geotechnical and Structural Engineering Research Center, Shandong University, Jinan 250061, China \\ ${ }^{4}$ Mining College, Guizhou University, Guiyang 550025, China
}

Correspondence should be addressed to Zhonghu Wu; wuzhonghugzu@163.com

Received 18 September 2020; Revised 18 December 2020; Accepted 21 December 2020; Published 7 January 2021

Academic Editor: Yixian Wang

Copyright (C) 2021 Zhonghu Wu et al. This is an open access article distributed under the Creative Commons Attribution License, which permits unrestricted use, distribution, and reproduction in any medium, provided the original work is properly cited.

Filling of brittle minerals such as quartz is one of the main factors affecting the initiation and propagation of reservoir fractures in shale fracturing, in order to explore the failure mode and thermal damage characteristics of quartz-filled shale under thermalmechanical coupling. Combining the theory of damage mechanics and thermoelasticity, $\mathrm{RFPA}^{2 \mathrm{D}}$-Thermal is used to establish a numerical model that can reflect the damage evolution of shale under thermal-solid coupling, and the compression test under thermal-mechanical coupling is performed. The test results show that during the temperature loading process, there is a temperature critical value between $60^{\circ} \mathrm{C}$ and $75^{\circ} \mathrm{C}$. When the temperature is less than the critical temperature, the test piece unit does not appear obvious damage. When the temperature is greater than the critical temperature, the specimen unit will experience obvious thermal damage, and the higher the temperature, the more serious the cracking. Under the thermalmechanical coupling of shale, the tensile strength and elastic modulus of shale show a decreasing trend with the increase of temperature. The failure modes of shale under thermal-solid coupling can be roughly divided into three categories: "V"-shaped failure $\left(30^{\circ} \mathrm{C}, 45^{\circ} \mathrm{C}\right.$, and $\left.75^{\circ} \mathrm{C}\right)$, "M"-shaped failure $\left(60^{\circ} \mathrm{C}\right)$, and inverted " $\lambda$ "-shaped failure $\left(90^{\circ} \mathrm{C}\right)$. The larger the fractal dimension, the more complex the failure mode of the specimen. The maximum fractal dimension is 1.262 when the temperature is $60^{\circ} \mathrm{C}$, and the corresponding failure mode is the most complex " $\mathrm{M}$ " shape. The fractal dimension is between 1.071 and 1.189 , and the corresponding failure mode is " $\mathrm{V}$ " shape. The fractal dimension is 1.231 , and the corresponding failure mode is inverted " $\lambda$ " shape.

\section{Introduction}

With the rapid consumption of conventional energy such as petroleum, unconventional clean energy such as shale gas has become a current research focus [1-5]. Shale gas refers to the natural gas resources that remain in shale reservoirs in the form of adsorption and dissociation during the evolution of geological structures. It has the characteristics of wide distribution, many developed layers, and large storage capacity [6-9]. It is predicted that my country's recoverable shale gas can reach $36.1 \times 10^{12} \mathrm{~m}^{3}$, ranking first in the world [10, 11]. The shale matrix has the characteristics of small pore throats and extremely low permeability. More than $90 \%$ of shale gas wells need to undergo shale reservoir fracturing before they can be directly put into production [12-14]. The research on shale gas in my country started late. How to achieve large-scale exploitation of shale gas has important strategic significance for the upgrading of my country's energy structure and green and sustainable development.

The fracturing of shale reservoirs uses high-pressure fluid to break the rock mass to form a complex fracture network with high permeability according to Jiang et al. [15]. Because shale gas reservoirs are in an environment of high confining pressure and high temperature, during the fracturing process, shale mining involves the mutual coupling of stress field and temperature field. Therefore, the problem of shale 
thermal damage is currently a hot topic for scholars at home and abroad. Meng et al. [16] conducted triaxial compression tests on shale samples whose temperature varied between 25 and $120^{\circ} \mathrm{C}$ to study temperature and shale peak strength, elastic modulus, Poisson's ratio, cohesion, and the relationship between the internal friction angles. Masri et al. [17] conducted triaxial compression tests on shale at different temperatures and found that the elastic modulus and compressive failure strength of shale decreased significantly as the temperature increased, but the overall deformability of shale increased. Mohamadi et al. [18] conducted a series of triaxial tests on shale at different temperatures and discussed in detail the influence of temperature on shale strength. Jha et al. [19] conducted uniaxial compression tests and tensile strength tests at different temperatures from normal temperature to $900^{\circ} \mathrm{C}$ and studied in detail the influence of high temperature on the physical and mechanical properties and uniaxial compressive strength of shale. Rybacki et al. [20] conducted creep tests on shale with different temperatures $\left(50 \sim 200^{\circ} \mathrm{C}\right)$ and different confining pressures $(50 \sim 200 \mathrm{MPa})$ to study the influence of temperature and confining pressure on creep characteristics. Wang et al. [21] conducted multistage creep tests on shale samples under different temperatures and confining pressures to study the effects of temperature, confining pressure, and precrack on shale creep characteristics. Guo et al. [22] conducted uniaxial compression tests and acoustic emission tests on shale samples with different bedding surface dip angles at different temperatures and studied the effect of temperature on the physical and mechanical properties of shale. Yang et al. [23] conducted dynamic compression tests on shale specimens in the temperature range of $20 \sim 220^{\circ} \mathrm{C}$, studied the mechanical properties of shale at different temperatures, and analyzed the dynamic deformation and failure process of shale.

Fractal theory has unique advantages in characterizing complex and irregular objects, and it provides a new theoretical basis for the evolution process of rock failure. Xie [24] combined fractal geometry with rock damage mechanics and proposed that the failure process of rock has fractal characteristics. Acoustic emission is a phenomenon of instantaneous elastic waves caused by the rapid release of local energy of the rock. Acoustic emission can reflect the change of the nature and state of the rock mass to a certain extent. Through the analysis of the change law of acoustic emission parameters, we can understand that the rock mass suffers using the characteristics of self-similarity of acoustic emission and further use fractal theory to analyze the failure process of rock mass. Yuan and $\mathrm{Li}$ [25] analyzed the fractal dimension of acoustic emission spatial distribution during rock damage and failure and established the relationship between stress and energy release and the fractal dimension of acoustic emission spatial distribution. Xie et al. [26] used a box dimension to calculate the fractal dimension of acoustic emission spatial distribution and studied the relationship between rock damage and acoustic emission fractal dimension. Zhang et al. [27] analyzed the fractal dimension of the spatial distribution of acoustic emission generated by the Brazilian split test and found that the fractal dimension can well reflect the initiation and expansion of rock microcracks.
Lou et al. [28] analyzed the spatial distribution characteristics of acoustic emission of different bedding shale under fluidmechanical coupling through numerical simulation experiments. It is found that the fractal dimension of the spatial distribution of acoustic emission can well reflect the influence of bedding on the failure mode of shale.

Shale is a kind of brittle rock formed by transportation and sedimentation in the process of geological structure evolution. The shale is filled with a large number of mineral particles. Under the action of temperature, the shape and content of mineral particles have a significant impact on the macro and micromechanical properties and fracture modes of shale [29-32]. Although there are many studies on the mechanical properties of shale at different temperatures, they mainly focus on the macroscale aspects such as bedding effects, different confining pressures, and creep studies. There are few reports on the micromechanical properties and failure modes of quartz-containing mineral-filled shale under temperature. Therefore, numerical simulation experiments are carried out on the microscale of shale to study the influence of thermal-mechanical coupling on the compressive strength, failure process, and failure mode of shale. The test results have an important reference value for the fracture initiation and propagation mechanism of fracturing reformation in shale reservoirs.

This article uses statistical methods to describe the heterogeneity of quartz and shale matrix. Through the RFPA $^{2 \mathrm{D}}$-Thermal software, the shale is subjected to numerical simulation tests under constant confining pressure and different temperature conditions, and the compressive strength, elastic modulus and failure process of shale under different temperature conditions are studied in detail. Calculate the fractal dimension of the acoustic emission distribution map and analyze the relationship between the fractal dimension and the failure mode under different temperature conditions. The research results will have an important reference value for fracture mechanism, secondary crack initiation and propagation prediction, and enhanced oil recovery in shale fracturing.

\section{Regional Geological Characteristics}

Guizhou is one of my country's oil and gas storage bases. The regional tectonic unit is divided into the Yangtze quasiplatform. Between hilly basins, the terrain is high in the west and low in the east and descends from the center to the north, east, and south. According to the distribution of surface structures, the metamorphic rock forms and structural combination styles of the area and other structural features. The study area has mainly experienced four tectonic cycles during the evolution of geological structure: Wuling tectonic movement, Caledonian-Xuefeng tectonic movement, Yanshan tectonic movement, and Himalayan tectonic movement. Among them, the Yanshanian period is the most intense tectonic movement, which is the main cause of the current topography. The Himalayan period superimposed and transformed the structures formed in the Yanshan period [33]. Shale gas reservoirs are mainly located in the Lower 


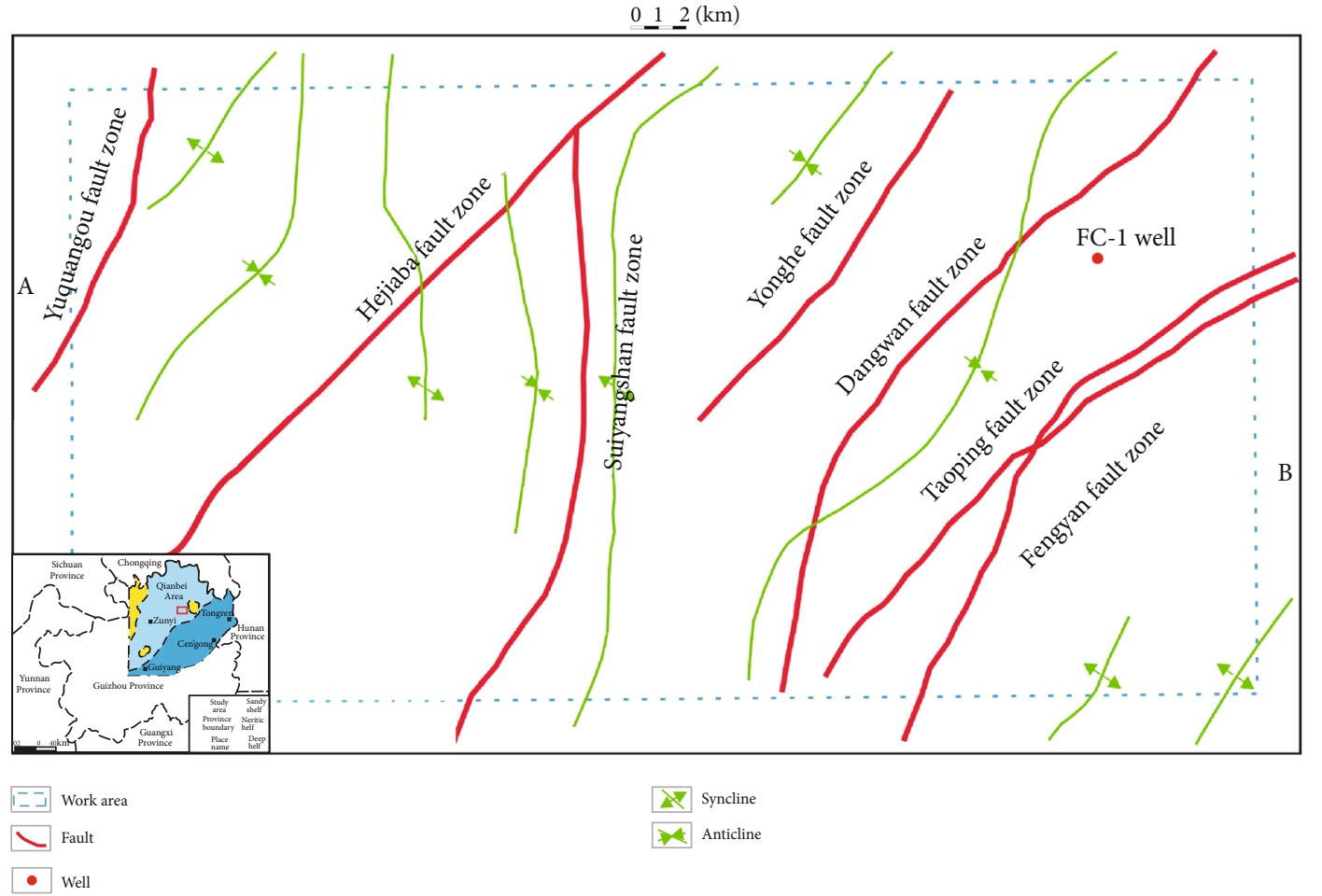

Figure 1: Area map of the third block of Fenggang, Qianbei, Guizhou [7, 34].

Cambrian Niutitang Formation, which is also the most widely developed bottom layer in Guizhou, as shown in Figure 1.

The study of rock and mineral characteristics is an important factor that needs to be considered in the exploration and development of shale gas. The higher the content of brittle minerals in shale, the more likely it is to produce cracks under the action of tectonic stress or hydraulic fracturing, providing storage space and seepage channel for shale gas. It can be seen that the shale is filled with a large amount of quartz through the microsection identification. The identification process and results are shown in Figure 2. Generally, the lower the clay mineral content in shale, the higher the brittle mineral content such as quartz, feldspar, and calcite, and the stronger the rock brittleness, the easier it is to form natural cracks and induced cracks under tectonic stress field or artificial fracturing $[35,36]$. The shale mineral composition in the study area is complex and diverse, of which clay minerals and brittle minerals are the main components in shale. This article mainly takes the black shale of the Lower Cambrian Niutitang Formation in Fenggang III District as the research object. Carrying out X-ray diffraction quantitative analysis and clay mineral analysis, the instrument model is X'pert powder. X-ray diffraction analysis is shown in Figure 3. The analysis results show that the quartz content is between $35.79 \%$ and $92.49 \%$, with an average content of $62.09 \%$. The content of plagioclase is $0-28.94 \%$, with an average of $12.32 \%$. The clay mineral content is $0-29.15 \%$, with an average of $7.64 \%$. It also contains a small amount of minerals such as pyrite, calcite, potash feldspar, and iron dolomite, with an average content of $7.50 \%, 3.99 \%, 3.24 \%$, and $2.96 \%$, respectively (Figure 4 ). As the buried depth increases, the quartz content gradually increases, while the plagioclase and pyrite content gradually decreases. Except for a few parts in the middle, the content of clay minerals is relatively high, and the overall decreases gradually (Figure 5).

Shale reservoirs have the characteristics of low permeability and micronano pore development. This lowpermeability and microporosity feature has an important influence on the content and storage of shale gas. As the main storage space of gas reservoirs, shale micropores determine the enrichment degree of shale gas reservoirs. Generally speaking, the more developed the microfractures and pores of shale, the higher the flow capacity and the richer the gas reservoir. In this paper, the relaxation of nuclear magnetic resonance (NMR) technology is used to characterize the pore structure of shale. The experimental instrument model is MesoMR23-060H-I. Five groups of samples in the study area are selected for detection and analysis. The results show that the pore throats of the Lower Cambrian shale in Fenggang III block are mainly nanopores, which are distributed between 0 and $0.1 \mu \mathrm{m}$. The pores of shale are mainly nanopores, and the pores are concentrated between $0.001 \mu \mathrm{m}-0.01 \mu \mathrm{m}$ and 0.01 $0.4 \mu \mathrm{m}$, and there are also a few micron-sized pores. The pore size distribution is shown in Figure 6.

\section{Thermal-Mechanical Coupling Model of Shale Microscopic Unit}

3.1. Thermal Damage Theory of Shale Microscopic Units. Based on the theory of continuum mechanics, shale is considered to be an ideal linear elastic body, which satisfies the generalized Hooke's law under external load [37]. A damage model of the microunit is established to characterize the 


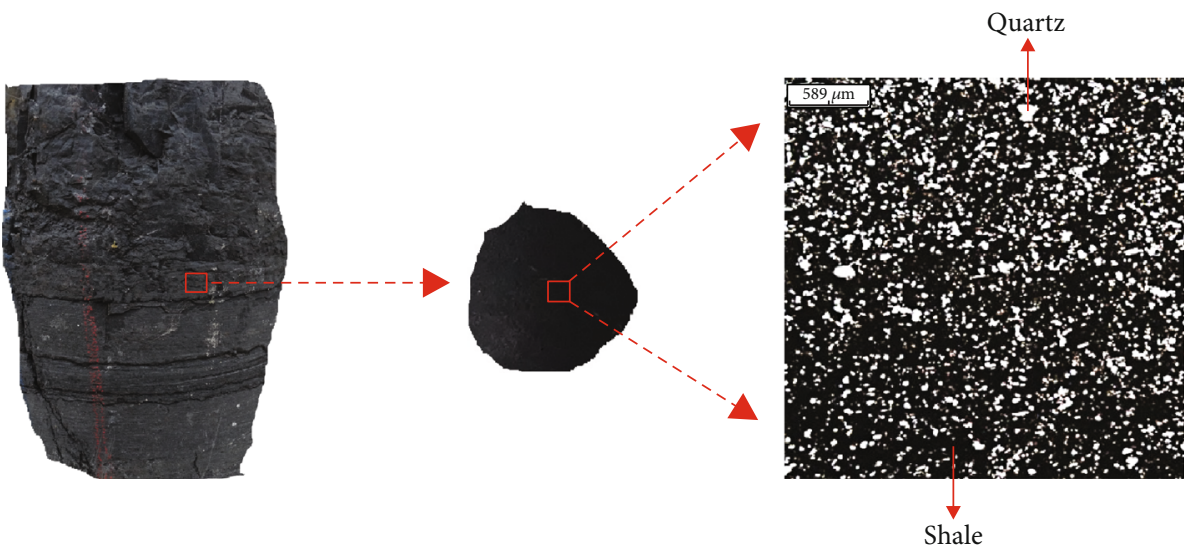

FiguRe 2: Verification diagram of microsection.

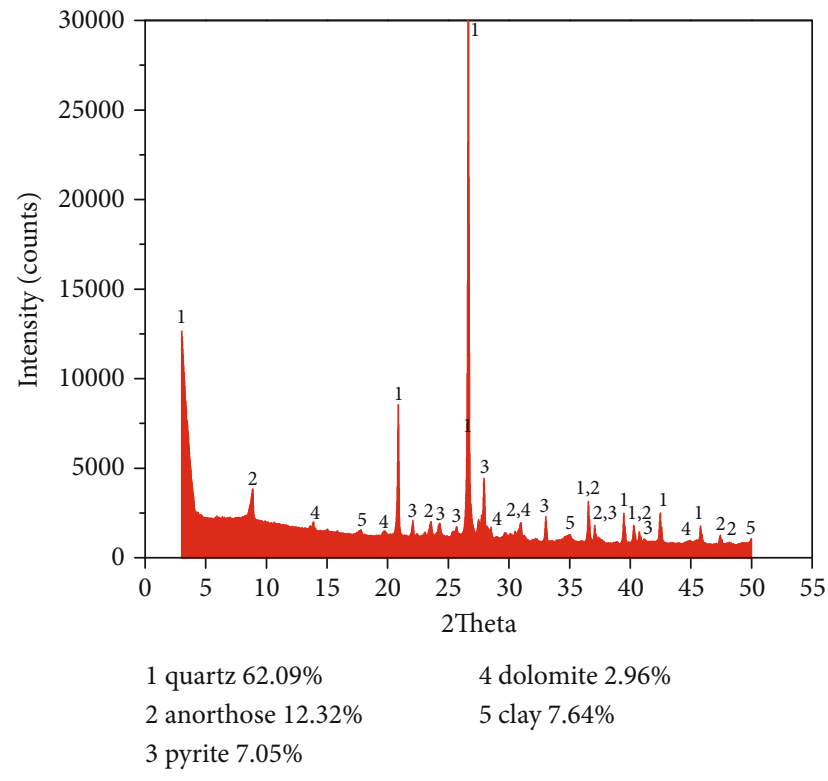

Figure 3: X-ray diffraction analysis of whole rock.

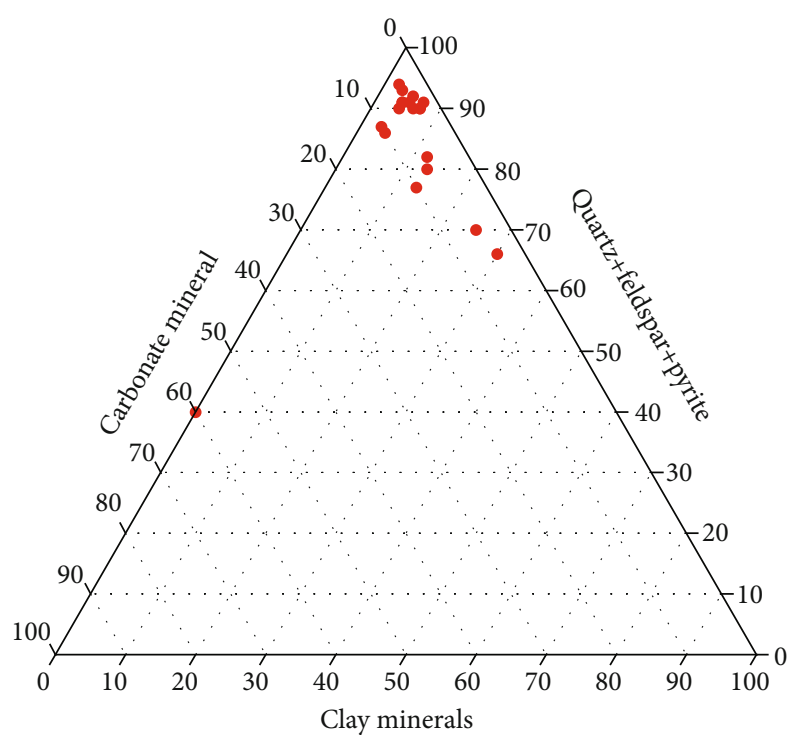

FIGURE 4: Mineral content map of shale reservoir. evolution process of shale damage under the thermalmechanical coupling action and its influence on elastic modulus and compressive strength. Because the compressive strength of shale is much greater than its tensile strength, under the action of external load, the maximum tensile stress criterion and Mohr-Coulomb criterion are used as the basis for judging element damage, and the maximum tensile stress criterion has priority. When the stress state of the shale reaches the critical state of the Mohr-Coulomb criterion, the unit begins to undergo shear failure. The above two judgment failure criteria are expressed as Equation (1) and Equation (2) [38]:

$$
\begin{gathered}
F_{1}=\sigma_{1}-f_{\mathrm{t} 0}, \\
F_{2}=-\sigma_{3}+\sigma_{1} \frac{1+\sin \theta}{1-\sin \theta}-f_{c 0},
\end{gathered}
$$

where $F_{1}$ and $F_{2}$ are functions of the maximum tensile stress criterion and Mohr-Coulomb criterion, respectively; $\sigma_{1}$ and $\sigma_{3}$ are the first and third principal stresses, respectively; $f_{t 0}$ and $f_{c 0}$ are uniaxial tensile strength and uniaxial compression strength, respectively; $\theta$ is the internal friction angle of shale.

3.2. Shale Thermal-Mechanical Coupling Relationship. This article considers the high temperature and high-pressure environment of shale, which involves the coupling relationship between temperature field and stress field. Through the control equations of stress field and temperature field, the damage evolution process of shale under external force and the influence of damage on stress field and temperature field are considered. Under the coupling effect of temperature field and stress field, microcracks in shale begin to sprout, and the damage of shale in turn affects the elastic modulus, compressive strength, and thermal conductivity of shale. Considering the effect of thermal stress on shale deformation caused by the temperature field, the stress-strain relationship of shale can be expressed as Equation (3) [39]:

$$
\sigma_{i j}=2 G \varepsilon_{i j}+\lambda \varepsilon_{k k} \delta_{i j}-\beta_{T} \triangle T \delta_{i j}
$$




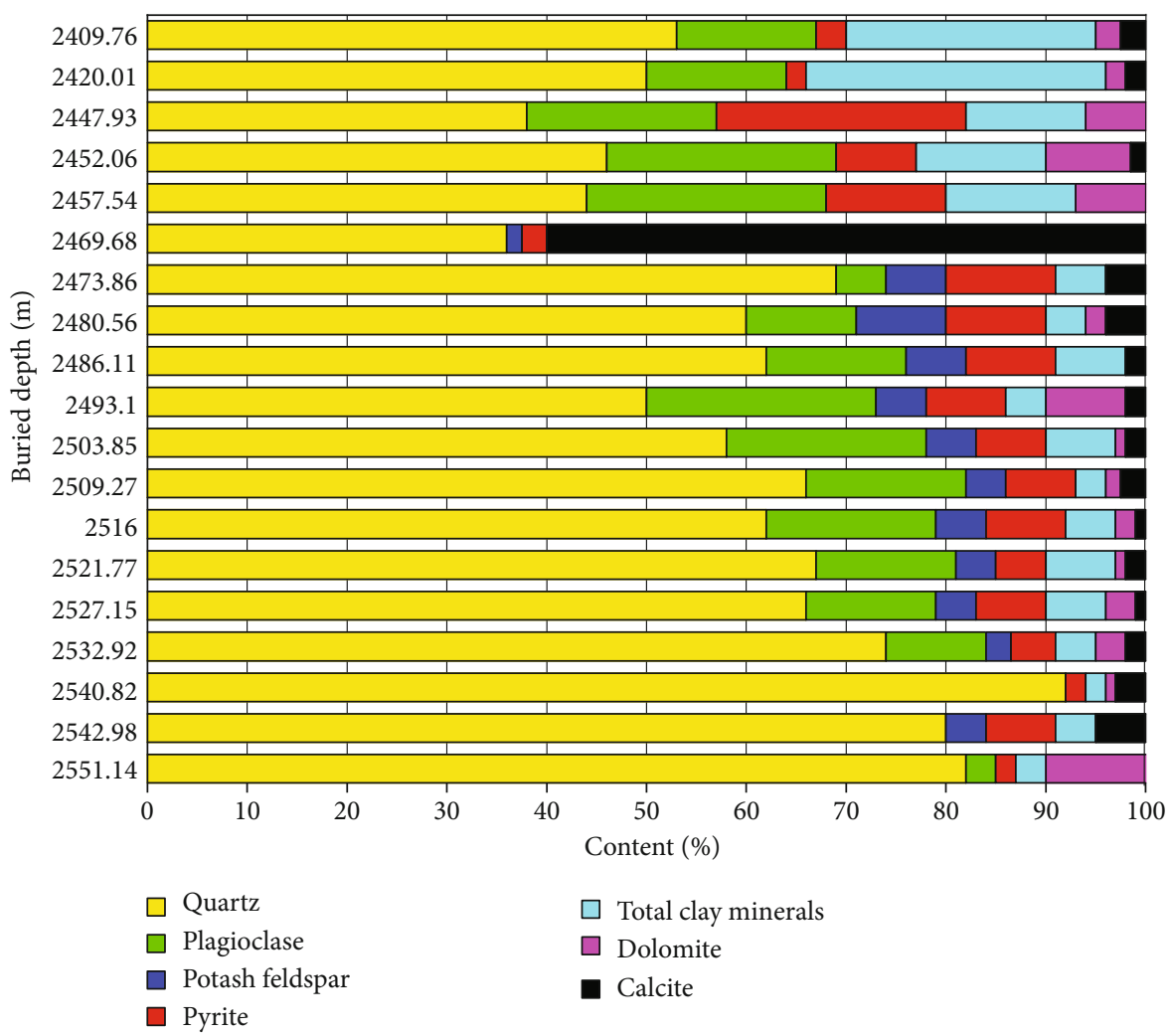

FIgURE 5: Distribution map of shale mineral content [7].

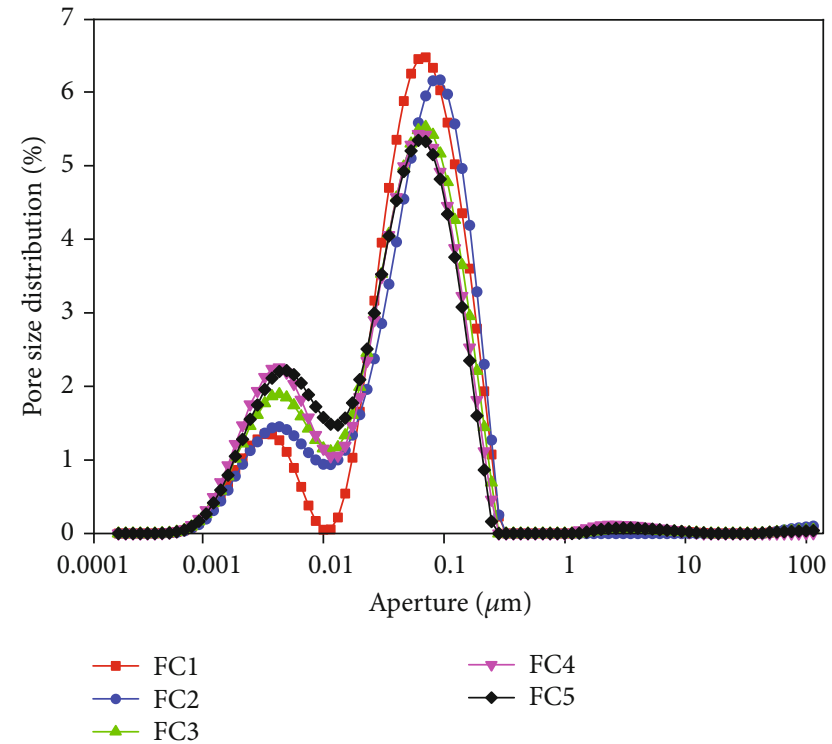

FIgURE 6: Pore size distribution diagram.

where $\sigma_{i j}$ is the stress tensor; $\varepsilon_{i j}$ is the strain tensor; $G$ is the shear modulus of the shale, $G=E / 2(1+v) ; \varepsilon_{v}$ is the volumetric strain; $\delta_{i j}$ is the Kronecker function; $k$ is the bulk modulus of shale; $\beta_{T}$ is the thermal stress coefficient of shale, $\beta_{T}=(3 \lambda+2 G) \alpha$, where $\lambda$ and $\alpha$ are Lame constant and thermal expansion coefficient, respectively; $\Delta T$ is the amount of temperature change.
The thermal conductivity of shale is closely related to temperature and reflects the unevenness of shale temperature field. Regarding the thermophysical properties of the shale microscopic unit, when the damaged unit is not initiated, the thermal conductivity $k$ of the shale is constant. The heat transfer coefficient $k(T)$ of shale after element tensile damage is calculated as Equation (4) [40]. The specific heat capacity of shale is also affected by temperature. The specific heat capacity $c(T)$ of the unit under tension of the shale is calculated according to Equation (5) [40]:

$$
\begin{gathered}
k(T)=k_{0}-\left(k_{0}-2.01\right)\left[\exp \left(\frac{T-20}{T+130}\right)-1\right], \\
c(T)=c_{0}(1+\psi T) .
\end{gathered}
$$

In the formula, $k_{0}$ is the thermal conductivity at a temperature of $0^{\circ} \mathrm{C} ; c_{0}$ is the specific heat capacity of the shale at a temperature of $0^{\circ} \mathrm{C} . \psi$ is the impact factor, which is generally $3 \times 10-3$.

In the numerical model established in this paper, the mutual conversion between thermal energy and mechanical energy is ignored, and the energy conservation equation is calculated according to Equation (6) [41]:

$$
(\rho \mathrm{c}) \frac{\partial T}{\partial t}+\left(T_{0}+T\right) K \alpha_{T} \frac{\partial \varepsilon_{v}}{\partial t}=\lambda \nabla^{2} T,
$$


TABLE 1: Numerical model parameters.

\begin{tabular}{lccccccc}
\hline & $\begin{array}{c}\text { Elastic } \\
\text { modulus } E \\
/ \mathrm{MPa}\end{array}$ & $\begin{array}{c}\text { Compressive } \\
\text { strength } \sigma_{c} / \mathrm{MPa}\end{array}$ & $\begin{array}{c}\text { Poisson's } \\
\text { ratio } v\end{array}$ & $\begin{array}{c}\text { Friction } \\
\text { angle }\left(^{\circ}\right)\end{array}$ & $\begin{array}{c}\text { Thermal } \\
\left.\left.\text { conductivity/J.(m.s. } .^{\circ}\right)^{-}\right)^{-}\end{array}$ & $\begin{array}{c}\text { Heat } \\
\left.\text { capacity/(J.(kg. }{ }^{\circ} \mathrm{C}\right)^{-} \\
1\end{array}$ & $\begin{array}{c}\text { Thermal expansion } \\
\text { coefficient } /\left(10^{-6} .{ }^{\circ} \mathrm{C}^{-1}\right)\end{array}$ \\
\hline Shale & 51600 & 145 & 0.22 & 35 & 1250 & 1250 & 1.36 \\
Quartz & 96000 & 375 & 0.08 & 60 & 700 & 700 & 1.1 \\
\hline
\end{tabular}
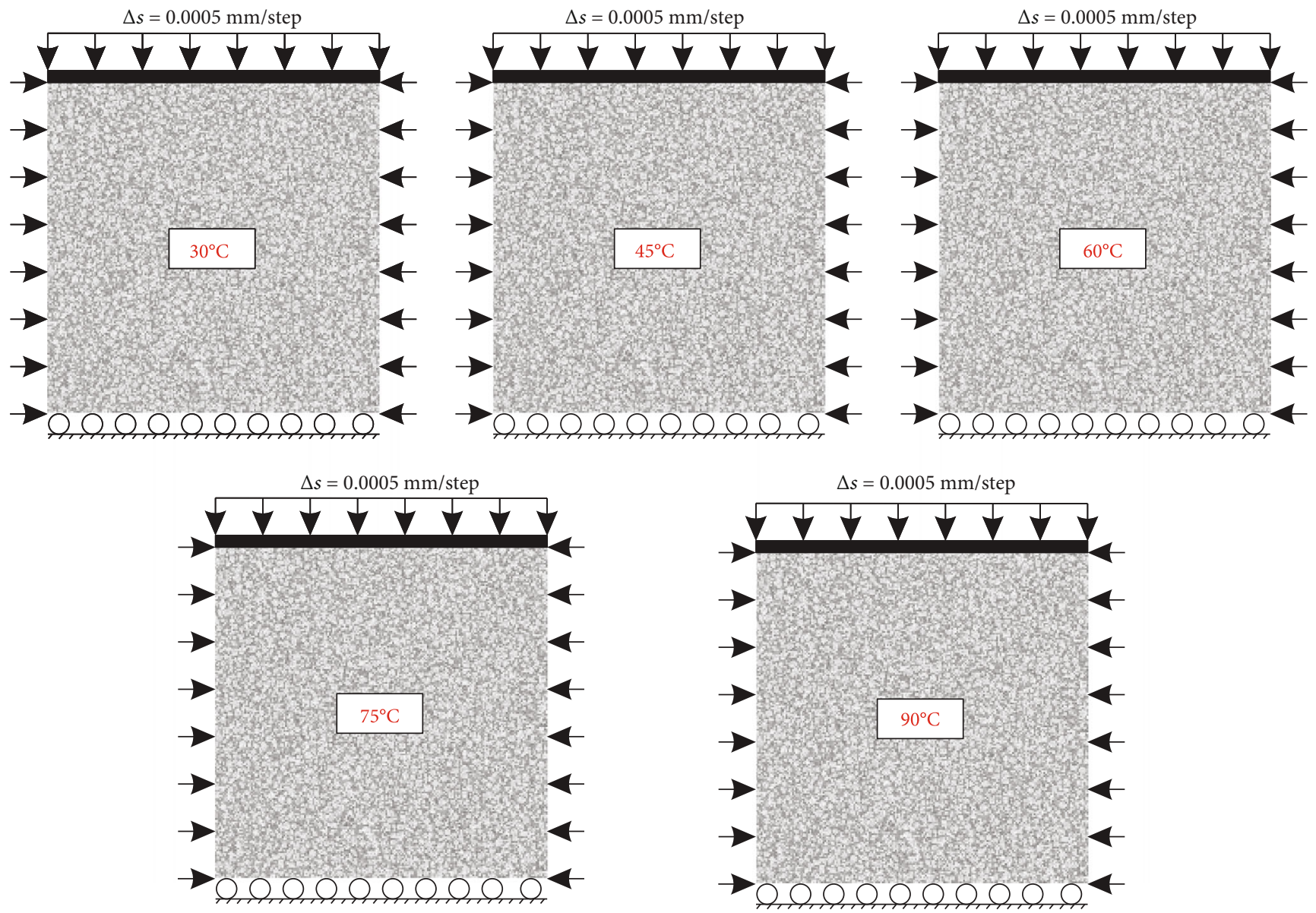

FIgURE 7: Model loading diagram.

where $T_{0}$ is the initial temperature of the shale; $\rho$ is the density of the shale; $c$ is the specific heat capacity of the shale; $\lambda$ is the thermal conductivity of the shale.

\section{Numerical Modeling}

RFPA $^{2 \mathrm{D}}$-Thermal is based on finite element theory and statistical damage theory. Considering the inhomogeneity of the rock, we simplified the complicated macro-nonlinear problem into a fine-to-microlinear problem and combined the assumption of random distribution of the inhomogeneity with numerical calculation methods. The numerical simulation of the nonuniform rock failure process can be realized [42]. The shale model is discretized into a numerical model composed of mesoprimitives. It is assumed that the mechanical properties of the discretized microprimitives obey the Weibull statistical distribution law, thereby establishing the relationship between the mechanical properties of the microand macromedium [43]:

$$
\varphi(\mu)=\frac{m}{\mu_{0}} \cdot\left(\frac{\mu}{\mu_{0}}\right)^{m-1} \cdot e^{-\left(\mu / \mu_{0}\right)^{m}} .
$$

In the formula, $\varphi(\mu)$ is the statistical distribution density of the mechanical property $\mu$ of shale primitives. $\mu$ is the mechanical property parameter of the shale element; $\mu_{0}$ is the average value of the mechanical property parameter of the shale element; $m$ is the property parameter of the distribution function, which reflects the uniformity of shale and is defined as the uniformity coefficient of shale.

In order to study the influence of temperature on the mechanical properties and failure modes of shale, this paper uses the RFPA ${ }^{2 D}$-Thermal software to establish a numerical 

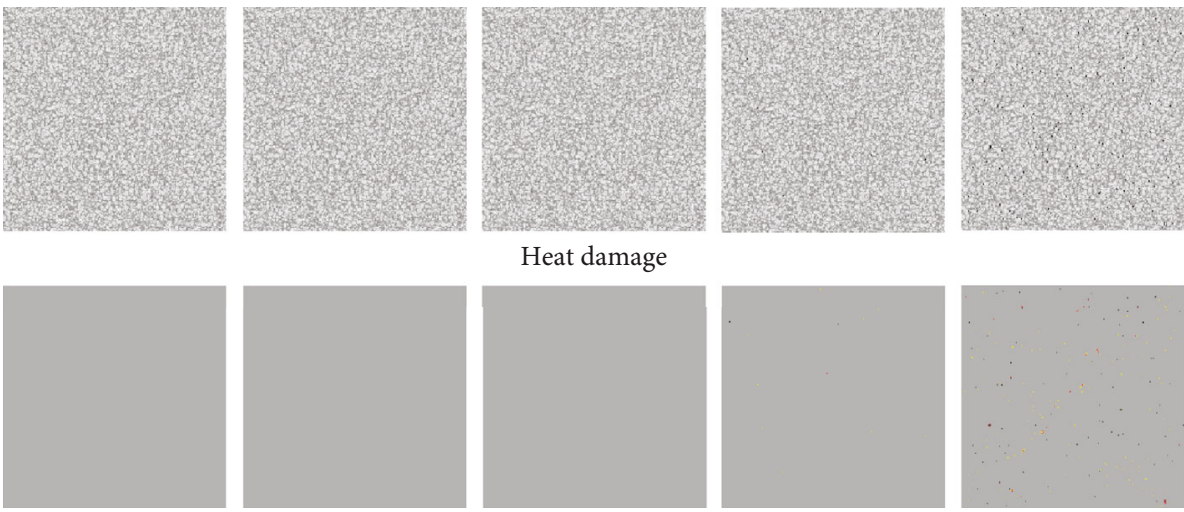

Heat damage

$30^{\circ} \mathrm{C}$

$45^{\circ} \mathrm{C}$
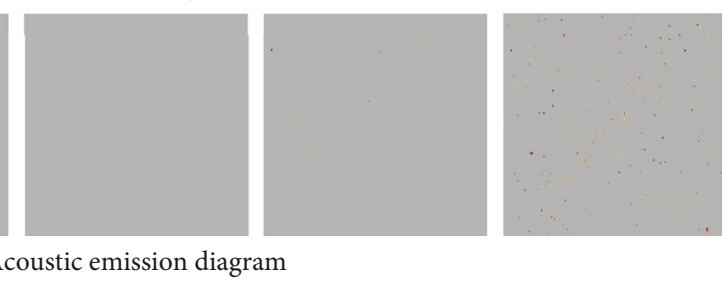

$60^{\circ} \mathrm{C}$

$75^{\circ} \mathrm{C}$

$90^{\circ} \mathrm{C}$

FIGURE 8: Thermal damage evolution process diagram of shale.

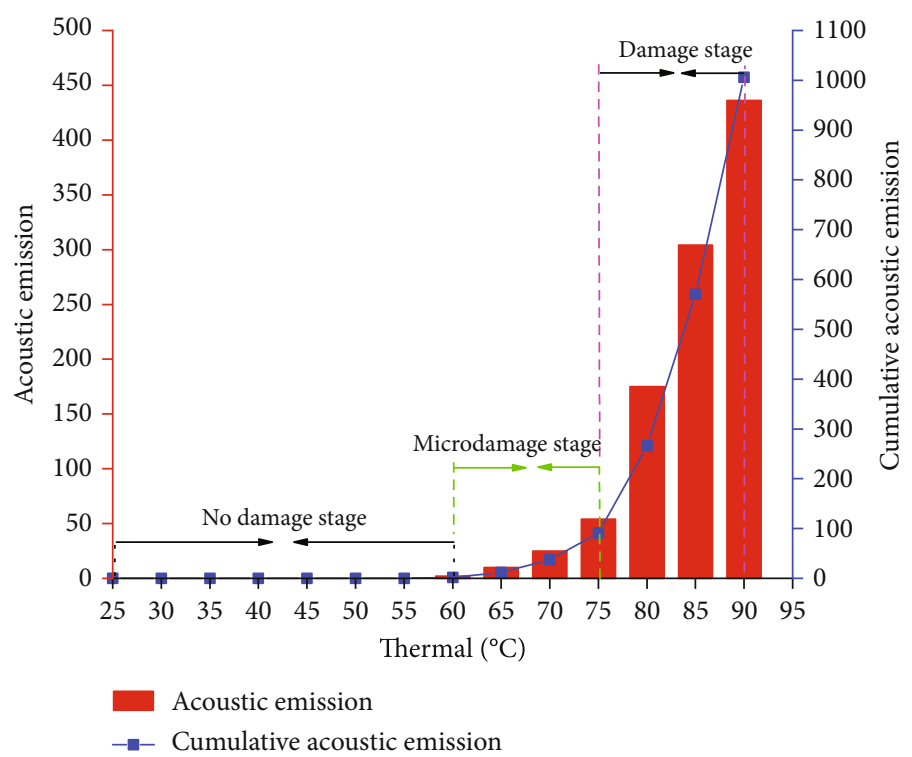

FIgURE 9: Variation of acoustic emission number with temperature

TABLE 2: Compressive strength and elastic modulus of shale under thermomechanical coupling.

\begin{tabular}{lcc}
\hline Temperature $/{ }^{\circ} \mathrm{C}$ & $\begin{array}{c}\text { Elastic } \\
\text { modulus/GPa }\end{array}$ & $\begin{array}{c}\text { Compressive } \\
\text { strength/MPa }\end{array}$ \\
\hline 30 & 84.92 & 79.79 \\
45 & 79.82 & 67.32 \\
60 & 77.31 & 52.59 \\
75 & 62.05 & 30.71 \\
90 & 54.88 & 10.15 \\
\hline
\end{tabular}

model and carries out simulation tests at different temperatures. In the numerical model, the larger the elastic modulus of the mineral particles, the brighter the color, which can be used to characterize the quartz mineral particles and the shale matrix. According to the physical experiments, the mechanical parameters and thermodynamic parameters of the quartz mineral and shale matrix in the model are shown in Table 1 [44].
This experiment establishes a numerical model of quartzfilled shale at different temperatures. The quartz content in the model is $62.09 \%$. Shale pores are mostly nanosized pores and a small amount of microsized pores. This test does not consider the influence of shale primary pores. The loading model is shown in Figure 7. During the loading process, a fixed confining pressure of $10 \mathrm{MPa}$ is applied first, and then, the temperature is loaded. When the temperature reaches $30^{\circ} \mathrm{C}, 45^{\circ} \mathrm{C}, 60^{\circ} \mathrm{C}, 75^{\circ} \mathrm{C}$, and $90^{\circ} \mathrm{C}$, the heating is stopped. The temperature is loaded step by step, and the increment is $5^{\circ} \mathrm{C} / \mathrm{step}$. After the temperature reaches a certain value, displacement loading is then carried out, and the displacement loading rate is $0.0005 \mathrm{~mm} / \mathrm{step}$.

\section{Result Analysis}

5.1. Thermal Damage Evolution Characteristics of Shale. Shale is often filled with brittle minerals such as quartz. Because the thermal expansion coefficients of brittle mineral 


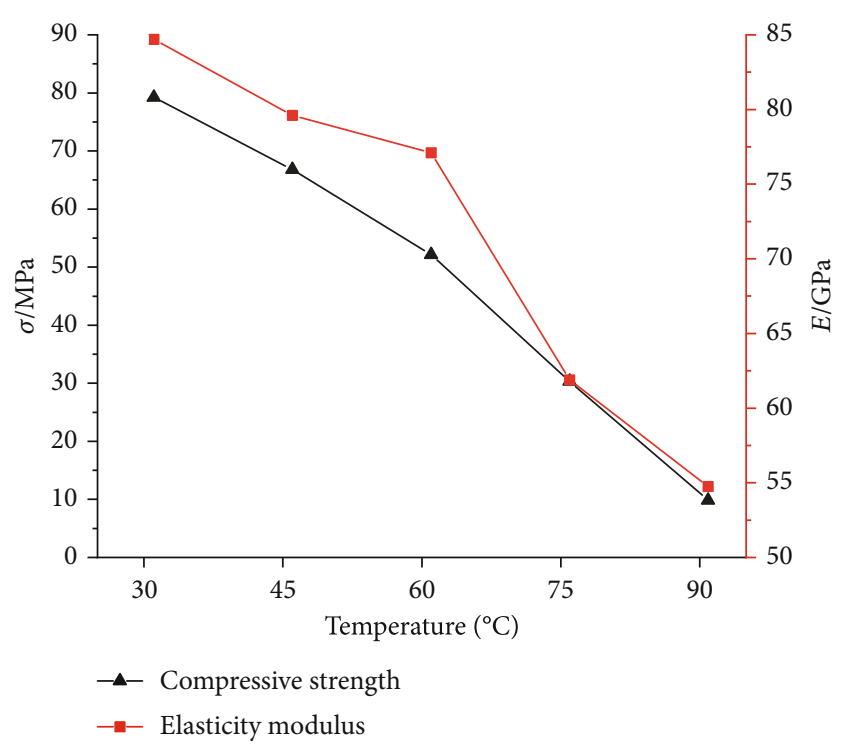

Figure 10: Compressive strength and elastic modulus of shale under thermal-mechanical coupling.

particles and shale matrix are different, the thermal expansion at the boundary between quartz and shale matrix is inconsistent, resulting in tensile or compressive thermal stress in the junction between quartz particles and shale matrix. Figure 8 is the damage distribution diagram and the corresponding acoustic emission diagram of the shale specimen at different temperatures. In the acoustic emission diagram, the yellow represents the tensile damage caused by the current step, the red represents the shear damage caused by the current step, and the black represents the damage. During the temperature loading process, there is a critical value of unit thermal damage temperature between $60^{\circ} \mathrm{C}$ and $75^{\circ} \mathrm{C}$. When the temperature is less than the critical value, the thermal stress does not cause obvious damage to the shale specimen. When the temperature is greater than the critical value, the local thermal stress is greater than the tensile strength of the shale specimen, and the specimen appears obvious microcracking. It can be seen from the acoustic emission diagram that the fracture is mainly tensile failure, and a small amount of shear failure occurs at $90^{\circ} \mathrm{C}$. The higher the temperature, the more serious the damage, and the microfractures are mainly distributed at the cementation between quartz and shale matrix. This is because quartz particles are randomly distributed in shale reservoirs, and the thermal expansion at the boundary between quartz and shale matrix is uncoordinated.

Acoustic emission number is the elastic wave signal of element damage initiation and release of shale specimen under thermal stress, reflecting the damage evolution process of specimen. Figure 9 is the change rule of acoustic emission number with temperature. During the temperature loading process, as the temperature increases, the number of acoustic emissions increases rapidly, and the corresponding thermal damage becomes more severe. The thermal damage evolution process of shale is divided into not damage stage, microdamage stage, and damage stage. When the temperature is less than the critical temperature, the acoustic emission num- ber is basically 0 , and there is no obvious damage to the shale sample. When the temperature reaches the critical temperature, the number of acoustic emissions and the cumulative number of acoustic emissions begin to appear, and the shale sample begins to appear microdamage. When the temperature reaches $80^{\circ} \mathrm{C}$, the thermal stress increases rapidly, and the thermal damage of the shale sample develops rapidly. This is consistent with the above-mentioned damage evolution process. The higher the temperature, the greater the number of acoustic emissions and the faster the cumulative number of acoustic emissions increases, indicating that the higher the temperature, the more severe the thermal damage of the shale specimen.

5.2. The Change Law of Shale Strength under ThermalMechanical Coupling. During the displacement loading process, the thermal-mechanical coupling effect of shale has a significant effect on the compressive strength and elastic modulus of shale filled with quartz minerals. Table 2 shows the strength and deformation parameters of shale obtained in the experiment, and Figure 10 shows the change trend graph of shale compressive strength and elastic modulus with temperature. With the increase of temperature, the tensile strength of shale shows a decreasing trend. The compressive strength is the largest at $30^{\circ} \mathrm{C}$, which is $79.79 \mathrm{MPa}$, and at $90^{\circ} \mathrm{C}$, the minimum is $10.15 \mathrm{MPa}$. The elastic modulus of shale shows a decreasing trend with the increase of temperature, and the most obvious change is between $60^{\circ} \mathrm{C}$ and $75^{\circ} \mathrm{C}$. The maximum elastic modulus is $84.9 \mathrm{GPa}$ at $30^{\circ} \mathrm{C}$, and the smallest at $90^{\circ} \mathrm{C}$ is $54.88 \mathrm{GPa}$. The thermal expansion of the quartz mineral particles and the shale matrix is uneven. The higher the temperature, the greater the thermal stress generated, and the mechanical properties of shale will weaken. When the temperature is greater than the critical temperature, the thermal stress is greater than the maximum tensile strength of the shale microscopic unit, and thermal damage occurs in the sample, which leads to increased nonuniformity of the shale. The higher the temperature, the more serious the microfracture and the lower the bearing capacity of shale in the displacement loading stage.

5.3. The Influence of Thermal-Solid Coupling on the Failure Process of Shale. Figure 11 shows the damage and failure process of shale under thermal-mechanical coupling and the corresponding acoustic emission diagram. It can be seen from the figure that different temperature effects have significant effects on the damage evolution and failure modes of shale, and the failure modes can be roughly divided into three categories. It is a " $\mathrm{V}$ "-shape failure when the temperature is $30^{\circ} \mathrm{C}, 45^{\circ} \mathrm{C}$, and $75^{\circ} \mathrm{C}$ and " $\mathrm{M}$ "-shape failure when the temperature is $60^{\circ} \mathrm{C}$. When the temperature is $90^{\circ} \mathrm{C}$, it is an inverted " $\lambda$ "-shape failure. When the temperature is $30^{\circ} \mathrm{C}$, cracks will initiate at the lower left corner of the specimen first. After the cracks appear, stress concentration will easily occur at both ends of the cracks, causing the cracks to rapidly propagate to both ends, and finally, a "V"-shaped crack is formed. When the temperature is $45^{\circ} \mathrm{C}$, cracks appear in the upper-right corner of the specimen under the combined action of thermal stress and loading stress. With continuous 

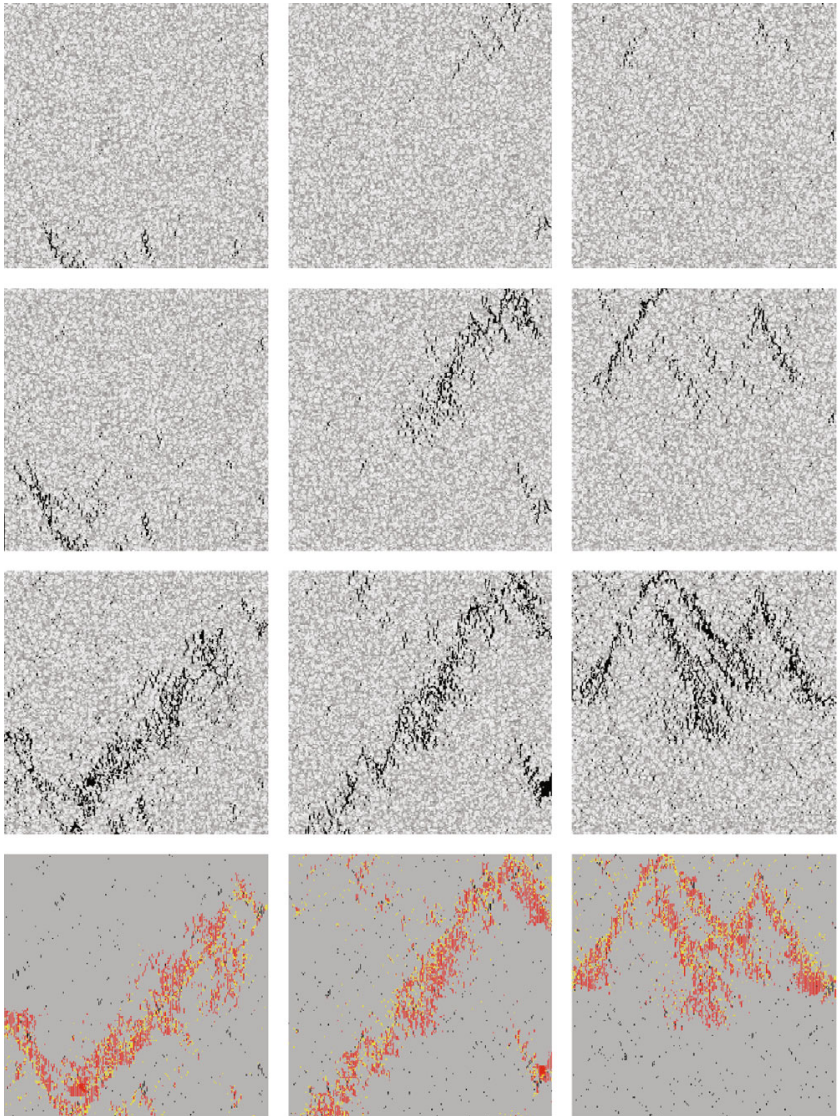

$30^{\circ} \mathrm{C}$

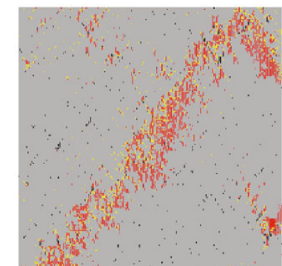

$45^{\circ} \mathrm{C}$
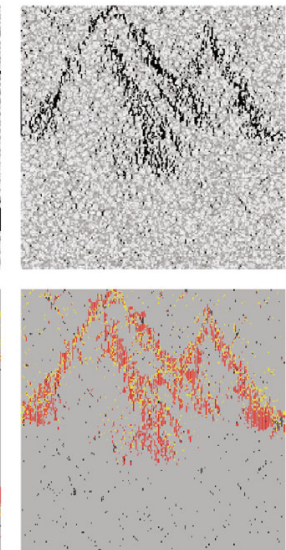

$60^{\circ} \mathrm{C}$
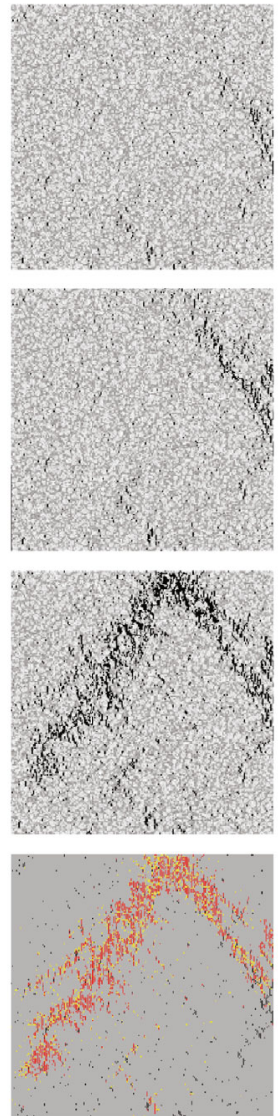

$75^{\circ} \mathrm{C}$
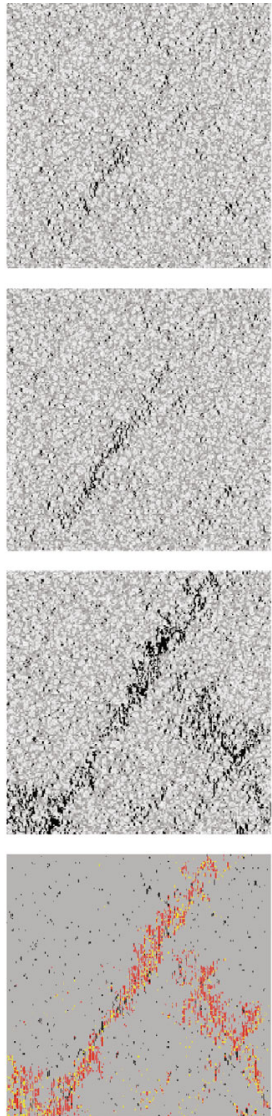

$90^{\circ} \mathrm{C}$

Figure 11: Damage evolution process diagram of shale under thermal-mechanical coupling.

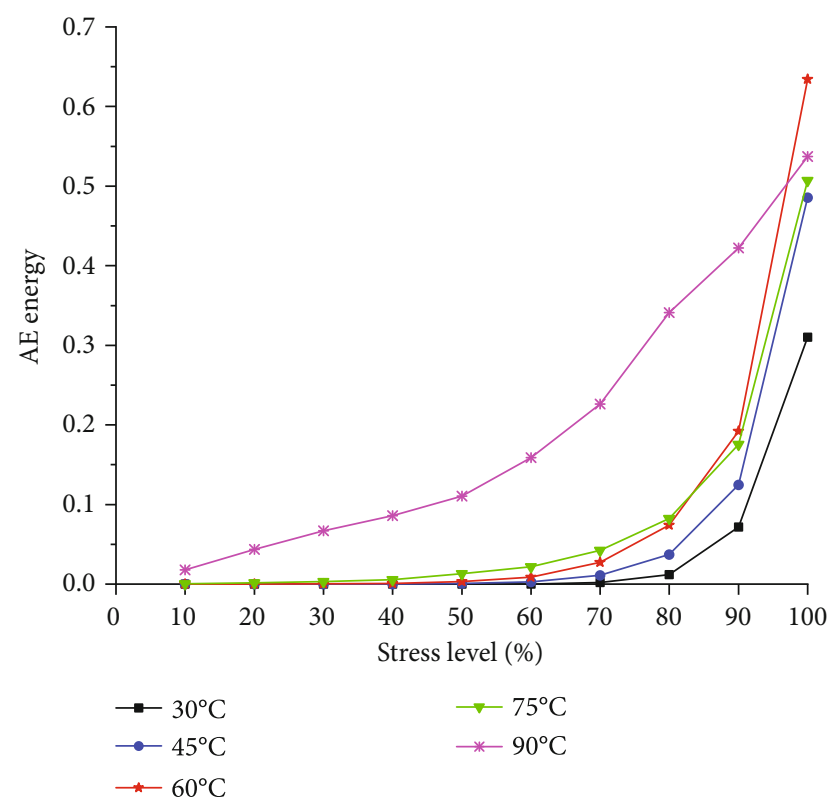

FIGURE 12: The relationship between stress level and AE energy under thermal-mechanical coupling.

loading, an inverted "V"-shaped crack is finally formed. When the temperature is $60^{\circ} \mathrm{C}$, the crack network during the instability and failure of the specimen is the most compli- cated, and the two cracks expand downward at the same time, forming an " $\mathrm{M}$ "-shaped fracture zone. When the temperature is $75^{\circ} \mathrm{C}$, microcracks first appear in the upper right corner, and finally form an inverted "V"-shaped fracture zone. When the temperature is $90^{\circ} \mathrm{C}$, the microcracks first appeared at the left end of the specimen and expanded along a straight line; then, the right-side microcracks appeared, quickly expanded to the left, and finally converged to form an inverted " $\lambda$ "-shaped fracture zone. Under the action of thermal-mechanical coupling, the higher the temperature, the rougher the cracks. The crack rupture zone at low temperature is smaller. The damage at high temperature mainly appears in the form of rupture zone, showing obvious plastic deformation. The main reasons for the above phenomenon are as follows: on the one hand, the uneven arrangement of quartz particles in the shale deposition process. The thermal expansion of quartz and shale matrix is quite different, resulting in unstable thermal stress under the action of temperature. As a result, thermal damage occurs at the boundary between the quartz and the shale matrix, and the bearing capacity of the shale specimen is reduced during displacement loading. On the other hand, the quartz mineral particles and crystals inside the rock undergo violent thermal movement under the action of temperature, which is more prone to microdamage. The strength of the quartz particles is greater than that of the shale matrix, the cracks are prone 
TABLe 3: AE energy and fractal dimension values.

\begin{tabular}{lcccccccccc}
\hline Stress level temperature & $10 \%$ & $20 \%$ & $30 \%$ & $40 \%$ & $50 \%$ & $60 \%$ & $70 \%$ & $80 \%$ & $90 \%$ & $100 \%$ \\
\hline $30^{\circ} \mathrm{C} \mathrm{AE}$ & 0 & 0 & 0 & 0 & 0 & 0.00011 & 0.00182 & 0.01169 & 0.07182 & 0.31024 \\
$D_{s}$ & 0 & 0 & 0 & 0 & 0 & 0.1632 & 0.4466 & 0.7057 & 0.9033 & 1.071 \\
$45^{\circ} \mathrm{C} \mathrm{AE}$ & 0 & 0 & 0 & 0.00006 & 0.00078 & 0.00276 & 0.01097 & 0.0372 & 0.12476 & 0.4857 \\
$D_{s}$ & 0 & 0 & 0 & 0.1818 & 0.3542 & 0.1754 & 0.6621 & 0.7938 & 0.9432 & 1.113 \\
$60^{\circ} \mathrm{C} \mathrm{AE}$ & 0 & 0.00006 & 0.0002 & 0.0008 & 0.00352 & 0.00859 & 0.02739 & 0.07412 & 0.19217 & 0.634 \\
$D_{s}$ & 0 & 0.1516 & 0.2137 & 0.4754 & 0.572 & 0.6931 & 0.8288 & 0.9183 & 1.127 & 1.262 \\
$75^{\circ} \mathrm{C} \mathrm{AE}$ & 0.00047 & 0.00143 & 0.00306 & 0.00553 & 0.01325 & 0.02197 & 0.04228 & 0.08221 & 0.17565 & 0.50713 \\
$D_{s}$ & 0.5432 & 0.6164 & 0.6677 & 0.7051 & 0.7926 & 0.8448 & 0.92 & 0.9928 & 1.072 & 1.189 \\
$90^{\circ} \mathrm{C} \mathrm{AE}$ & 0.01787 & 0.04349 & 0.06711 & 0.08616 & 0.11039 & 0.1587 & 0.22617 & 0.34097 & 0.4221 & 0.53713 \\
$D_{s}$ & 1.024 & 1.051 & 1.072 & 1.086 & 1.101 & 1.129 & 1.154 & 1.193 & 1.212 & 1.231 \\
\hline & & & & & & & & & &
\end{tabular}

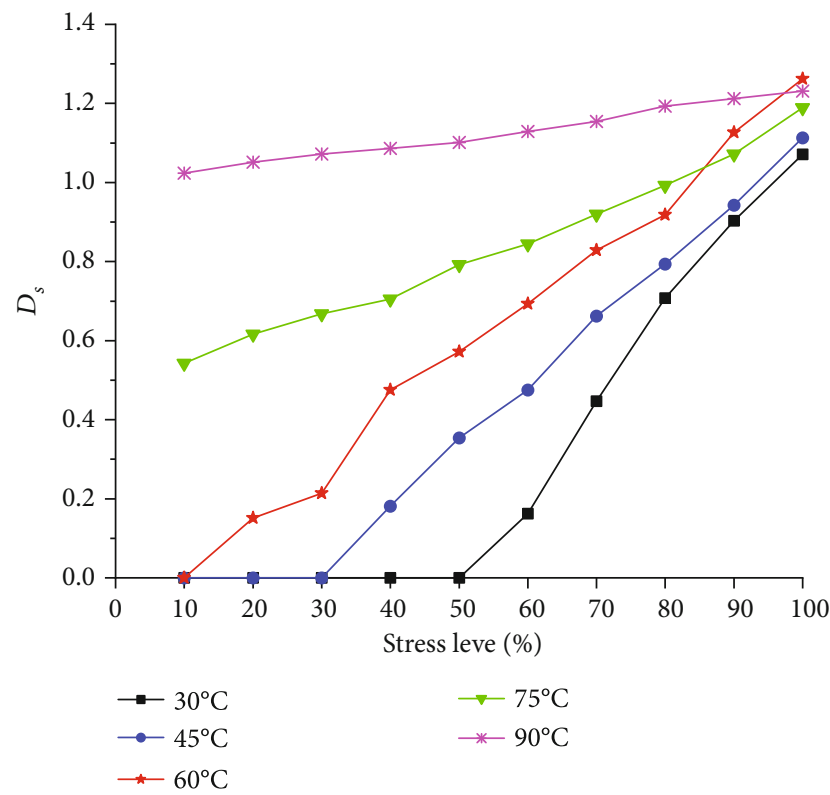

FIGURE 13: Relationship between stress level and fractal dimension under thermo-mechanical coupling.

to bend when they pass through the quartz, and the damage range is larger under the action of external load.

In the acoustic emission diagram, yellow represents the tensile failure initiated at the current step, red represents the shear damage caused by the current step, and black represents the damaged unit. Looking at the acoustic emission diagram, it can be seen that the shale specimens are mainly tensile-shear failure. The cracks when the specimen is instability and failure are connected by a tensile damage unit and a compression-shear damage unit. The cumulative damage development trend of microunits directly reflects the macrofailure mode of shale specimens. The joint action of thermal stress and external stress will cause tensile damage when the tensile strength of the specimen is first reached. As the loading process reaches the critical value of the Mohr-Coulomb strength criterion, the specimen unit appears compression-shear failure. The above results indicate that the heterogeneous microstructure of the quartz filled in shale under thermal-mechanical coupling has a significant impact on its damage evolution process and failure mode.

5.4. Fractal Characteristics of Shale Damage Evolution Process under Thermal-Solid Coupling. Figure 12 is a graph of the relationship between stress level and $\mathrm{AE}$ energy under thermal-solid coupling. It can be seen from the figure that temperature has a significant effect on the release of $\mathrm{AE}$ energy, and the law of energy release under the same stress level at different temperatures is significantly different. Due to the effect of thermal stress, at $90^{\circ} \mathrm{C}$, the shale specimen begins to microcrack when the stress level is $10 \%$, resulting in energy release. Except for the stress level at 100\%, the released energy is slightly lower than $60^{\circ} \mathrm{C}$, and the rest of the stress levels of the energy release is maximum. When the temperature is low $\left(30^{\circ} \mathrm{C}\right.$ and $\left.45^{\circ} \mathrm{C}\right)$, the $\mathrm{AE}$ energy release increases with the increase of temperature, and it is the smallest at $30^{\circ} \mathrm{C}$. When the temperature is high $\left(60^{\circ} \mathrm{C}\right.$, $75^{\circ} \mathrm{C}$, and $90^{\circ} \mathrm{C}$ ), the release of $\mathrm{AE}$ energy at peak stress is greater. The $\mathrm{AE}$ energy release at $60^{\circ} \mathrm{C}$ is the largest, followed by $90^{\circ} \mathrm{C}$, and the minimum is $75^{\circ} \mathrm{C}$. When the temperature is lower than the critical temperature of damage, there is almost no microfracture in the shale specimen under the action of thermal stress. Therefore, energy release begins when the stress level reaches $60 \%$ at low temperature. When the temperature is greater than the critical temperature of damage, due to the different thermal damages at different temperatures, the temperature is higher, and there is an earlier release of $\mathrm{AE}$ energy. At $75^{\circ} \mathrm{C}$, the stress level reaches $40 \%$ and the microcrack appears and starts to release energy.

Fractal theory can quantitatively describe complex objects in the world. It is widely used in the field of rock failure and helps to reveal the law of damage and fracture of rocks. In this paper, the fractal dimension of the image is calculated by the box dimension, and the fractal dimension program is written on the MATLAB software platform. Binarize the acoustic emission diagrams under different stress levels obtained in the experiment, and import the calculation 


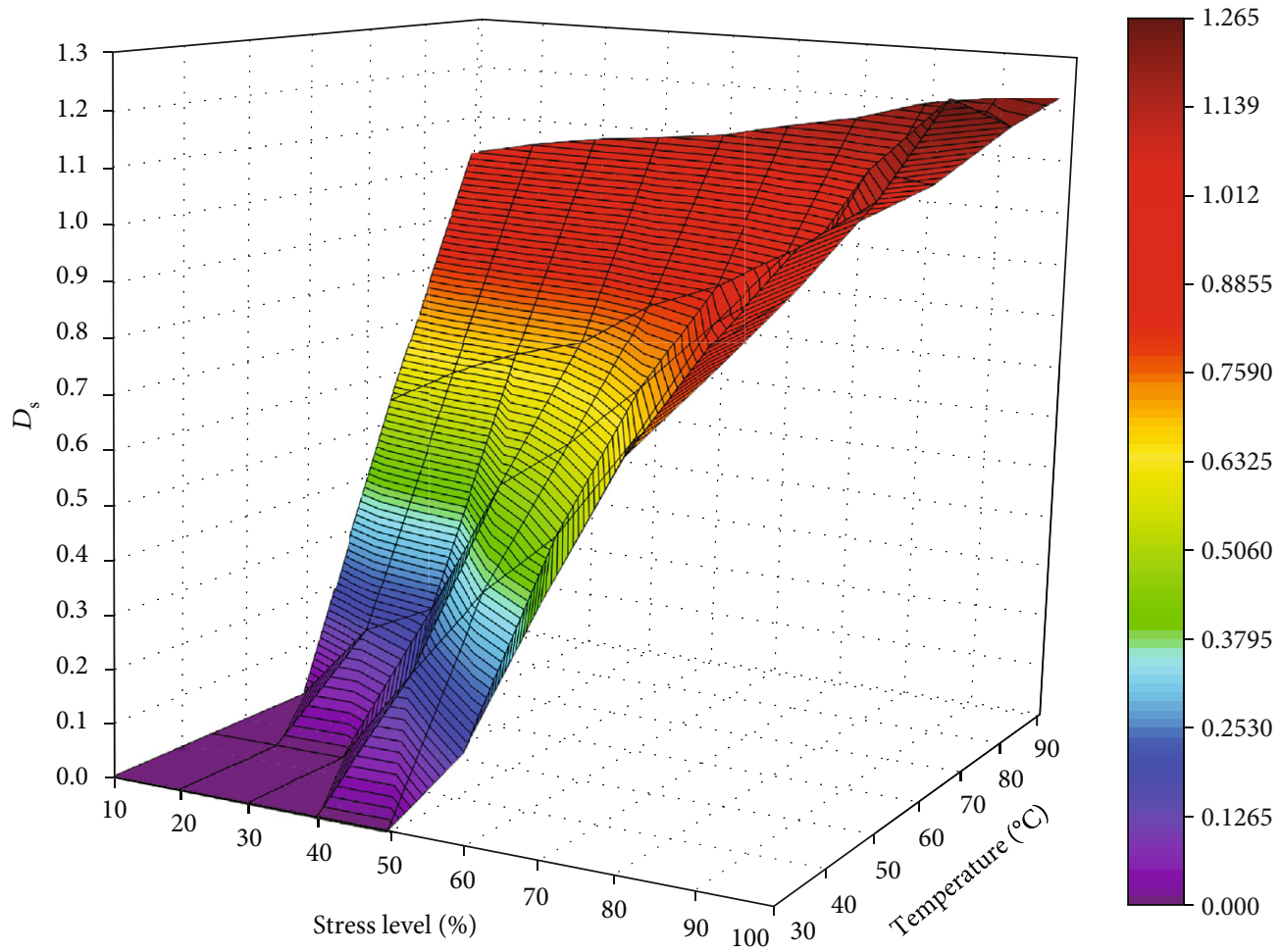

FIgURE 14: Stress level-temperature-fractal dimension relationship diagram.

program to obtain the fractal dimension of the acoustic emission diagrams. The formula is defined as follows:

$$
D_{s}=-\lim _{\gamma \rightarrow 0} \frac{\lg N(\gamma)}{\lg \gamma}
$$

where $D_{S}$ is the self-similar fractal dimension of the damage area; $\gamma$ is the side length of the square box; $N(\gamma)$ is the number of boxes required to cover the damaged area in the entire graph with a square box with side length $\gamma$.

Table 3 shows the AE energy and fractal dimension values. Figure 13 is a graph showing the change trend of fractal dimension with stress level under thermal-mechanical coupling. It can be concluded from the figure that under the effect of thermal-solid coupling, the fractal dimension increases with the increase of the stress level. Due to the incoordination of the thermal expansion coefficient between the quartz particles and the shale matrix during the temperature loading stage, thermal stress is generated, which leads to the initiation of thermal cracking of the specimen. The higher the temperature, the more serious the thermal cracking. When the temperature is less than the critical temperature of damage, the fractal dimension begins to appear after the stress level reaches $10 \%$, and the lower the temperature, the later it appears. When the temperature is greater than the critical temperature of damage, the fractal dimension begins to appear at the beginning of displacement loading. The fractal dimension is the lowest at $30^{\circ} \mathrm{C}$, which is 1.071 . The fractal dimension is the largest at $60^{\circ} \mathrm{C}$, which is 1.262 , and the corresponding failure mode is the most complicated " $\mathrm{M}$ " shape. The fractal dimension is $1.071 \sim 1.189$, and the corresponding failure mode is " $V$ " shape. The fractal dimension is 1.231 , and the corresponding failure mode is inverted " $\lambda$." The failure mode of the specimen is quantitatively analyzed by the fractal dimension. The larger the fractal dimension at peak stress, the more complex the failure mode, the rougher the crack, and the more severe the internal damage. The abovementioned content is depicted in a three-dimensional coordinate system. As shown in Figure 14, we can clearly see the changing trend of stress level, temperature, and fractal dimensions. From the perspective of fractal, the influence of thermal-mechanical coupling on the failure mode of shale is confirmed.

\section{Conclusion}

Shale is often filled with quartz minerals, and the difference in thermal expansion between quartz particles and shale matrix is an important influencing factors of rock fracture under thermal-mechanical coupling. In this paper, the thermal-solid coupling model is established to study the influence of temperature on the mechanical properties and damage evolution process of quartz-filled shale, and the following rules are summarized:

(1) The quartz content of the Niutitang Formation shale in the III District of Fenggang is 35.79\% 92.49\%, with an average content of $62.09 \%$. As the depth of burial increases, the overall quartz content gradually increases. Shale pore throats are mainly nanopores distributed between 0 and $0.1 \mu \mathrm{m}$. Shale pores are concentrated between $0.001 \mu \mathrm{m} \sim 0.01 \mu \mathrm{m}$ and $0.01 \sim 0.4 \mu \mathrm{m}$, mainly nanopores, with a few micron-sized pores 
(2) The effect of temperature has a significant effect on the thermal damage of shale filled with a large amount of quartz. The evolution process of thermal damage can be divided into nondamage stage, microdamage stage, and damage stage. There is a critical temperature value. When the temperature is greater than the critical temperature, the specimen unit will experience obvious thermal cracking. The higher the temperature, the more serious the cracking. The thermal-mechanical coupling effect has a significant effect on the compressive strength and elastic modulus of shale filled with quartz minerals. With the increase of temperature, the tensile strength and elastic modulus of shale show a decreasing trend

(3) Temperature has a significant influence on the damage evolution and failure modes of shale under thermosolid coupling. The failure modes can be roughly divided into three categories. When the temperature is $30^{\circ} \mathrm{C}, 45^{\circ} \mathrm{C}$, and $75^{\circ} \mathrm{C}$, it is a " $\mathrm{V}$ "-shape failure; when the temperature is $60^{\circ} \mathrm{C}$, it is an " $\mathrm{M}$ "-shape failure; when the temperature is $90^{\circ} \mathrm{C}$, it is an inverted " $\lambda$ "-shape failure. The higher the temperature, the rougher the fracture will be. The damage at high temperature mainly appears in the form of rupture zone with obvious plastic deformation

(4) Using the self-similarity of the spatial distribution of acoustic emission points, we quantitatively analyze the influence of thermal-mechanical coupling on the failure mode of shale specimens based on fractal theory. The larger the fractal dimension, the more complicated the failure mode of the specimen and the more serious the internal damage. When the temperature is $60^{\circ} \mathrm{C}$, the fractal dimension is the largest, which is 1.262 , and the corresponding failure mode is the most complicated " $\mathrm{M}$ " shape. The fractal dimension is between 1.071 and 1.189, and the corresponding failure mode is " $V$ " shape. The fractal dimension is 1.231 , and the corresponding failure mode is inverted " $\lambda$ shape".

\section{Data Availability}

The data used to support the study is available within the article.

\section{Conflicts of Interest}

The authors declare that they have no conflicts of interest.

\section{Acknowledgments}

This study was supported by the Talent Introduction Project of Special Fund for Science and Technology of Water Resources Department of Guizhou Province (Project No. KT201804), Guizhou Postgraduate Innovation Fund (Project No. YJSCXJH[2020]087), Guizhou Science and Technology Fund (Project No. [2020]4Y046, Project No. [2019]1075, and Project No. [2018]1107), the National Natural Science Foundation of China (Project Nos. 51964007 and 51774101), and Project Scientific Research Project of Guiyang Rail Transit Line 2 Phase I Project (Project No. D2(I)FW-YJ-2019-001-WT). This study is also funded by the Teaching reform project of Guizhou University (Project
No. JG201990) and Guizhou Province Mine Dynamic Disaster Early Warning and Control Technology Innovation Talent Team Project (Project No. [2019]5619).

\section{References}

[1] D. Zhang, P. G. Ranjith, and M. S. A. Perera, "The brittleness indices used in rock mechanics and their application in shale hydraulic fracturing: a review," Journal of Petroleum Science and Engineering, vol. 143, pp. 158-170, 2016.

[2] C. Yan, J. Deng, Y. Cheng, M. Li, Y. Feng, and X. Li, "Mechanical properties of gas shale during drilling operations," Rock Mechanics and Rock Engineering, vol. 50, no. 7, pp. 17531765, 2017.

[3] G. Li, G. Li, Y. Wang, S. Qi, and J. Yang, "A rock physics model for estimating elastic properties of upper Ordovician- lower Silurian mudrocks in the Sichuan Basin, China," Engineering Geology, vol. 266, article 105460, 2020.

[4] L. Li, B. Huang, Y. Li, R. Hu, and X. Li, "Multi-scale modeling of shale laminas and fracture networks in the Yanchang formation, Southern Ordos Basin, China," Engineering Geology, vol. 243, pp. 231-240, 2018.

[5] Z. Shen, L. Zhou, X. Su, H. Li, J. Tang, and X. Zheng, "An experimental investigation of the nonlinear gas flow and stress-dependent permeability of shale fractures," Energy Science and Engineering, vol. 8, no. 8, pp. 2808-2822, 2020.

[6] R. Wang, Y. Gu, W. Ding et al., "Characteristics and dominant controlling factors of organic-rich marine shales with high thermal maturity: a case study of the Lower Cambrian Niutitang Formation in the Cen'gong block, southern China," Journal of Natural Gas Science and Engineering, vol. 33, pp. 81-96, 2016.

[7] Z. H. Wu, Y. J. Zuo, S. Y. Wang et al., "Numerical study of multi-period palaeotectonic stress fields in Lower Cambrian shale reservoirs and the prediction of fractures distribution: a case study of the Niutitang Formation in Feng'gang No. 3 block, South China," Marine and Petroleum Geology, vol. 80, pp. 369-381, 2017.

[8] S. Yin, R. Xie, Z. Wu, J. Liu, and W. Ding, "In situ stress heterogeneity in a highly developed strike-slip fault zone and its effect on the distribution of tight gases: a 3D finite element simulation study," Marine and Petroleum Geology, vol. 99, pp. 75-91, 2019.

[9] G. A. Yakaboylu, N. Gupta, E. M. Sabolsky, and B. Mishra, "Mineralogical characterization and strain analysis of the Marcellus shales," International Journal of Rock Mechanics and Mining Sciences, vol. 130, article 104345, 2020.

[10] C. Zou, R. Zhu, Z.-Q. Chen et al., "Organic-matter-rich shales of China,” Earth-Science Reviews, vol. 189, pp. 51-78, 2019.

[11] L. Wang, Y. Guo, C. Yang, J. Xiao, C. Lu, and Y. Song, "Mechanical characterization of continental shale in Sichuan Basin of China and its potential impact on reservoir stimulation," Journal of Natural Gas Science and Engineering, vol. 79, article 103346, 2020.

[12] R. WANG, Z. HU, S. LONG et al., "Differential characteristics of the Upper Ordovician-Lower Silurian Wufeng-Longmaxi shale reservoir and its implications for exploration and development of shale gas in/around the Sichuan Basin," Acta Geologica Sinica-English Edition, vol. 93, no. 3, pp. 520-535, 2019.

[13] Z. Wu, Y. Zuo, S. Wang, J. Sunwen, and L. Liu, "Experimental study on the stress sensitivity and influence factors of shale 
under varying stress," Shock and Vibration, vol. 2018, Article ID 3616942, 9 pages, 2018.

[14] A. Michael, J. E. Olson, and M. T. Balhoff, "Orientation prediction of fracture initiation from perforated horizontal wells: application in shale reservoirs," Journal of Petroleum Science and Engineering, vol. 193, article 107355, 2020.

[15] G. Jiang, J. Zuo, Y. Li, and X. Wei, "Experimental investigation on mechanical and acoustic parameters of different depth shale under the effect of confining pressure," Rock Mechanics and Rock Engineering, vol. 52, no. 11, pp. 4273-4286, 2019.

[16] L. B. Meng, T. B. Li, L. W. Jiang, and H. M. Ma, "Experimental study on the influence of temperature on shale mechanical properties under conventional triaxial compression," Advanced Materials Research, vol. 250-253, pp. 1452-1455, 2011.

[17] M. Masri, M. Sibai, J. F. Shao, and M. Mainguy, "Experimental investigation of the effect of temperature on the mechanical behavior of Tournemire shale," International Journal of Rock Mechanics and Mining Sciences, vol. 70, pp. 185-191, 2014.

[18] M. Mohamadi and R. G. Wan, "Strength and post-peak response of Colorado shale at high pressure and temperature," International Journal of Rock Mechanics and Mining Sciences, vol. 84, pp. 34-46, 2016.

[19] M. K. Jha, A. K. Verma, P. K. Gautam, and A. Negi, "Study of mechanical properties of Vindhayan shaly rocks at elevated temperature," Journal of the Geological Society of India, vol. 90, no. 3, pp. 267-272, 2017.

[20] E. Rybacki, J. Herrmann, R. Wirth, and G. Dresen, "Creep of Posidonia shale at elevated pressure and temperature," Rock Mechanics and Rock Engineering, vol. 50, no. 12, pp. 31213140, 2017.

[21] Y. Wang, H. Wang, and X. Shi, "Creep investigation on shalelike material with preexisting fissure under coupling temperatures and confining pressures," Advances in Civil Engineering, vol. 2019, Article ID 7861305, 10 pages, 2019.

[22] Y. Guo, C. Yang, L. Wang, and F. Xu, "Effects of cyclic loading on the mechanical properties of mature bedding shale," Advances in Civil Engineering, vol. 2018, Article ID 8985973, 9 pages, 2018.

[23] G. Yang, J. Liu, X. Li, and J. Bi, "Effect of temperature on shale strength under dynamic impact loading," Arabian Journal of Geosciences, vol. 13, no. 12, 2020.

[24] H. Xie, An Introduction to Fractal-Rock Mechanics, Science Press, Beijing, 1996.

[25] R.-f. Yuana and Y.-h. Li, "Fractal analysis on the spatial distribution of acoustic emission in the failure process of rock specimens," International Journal of Minerals, Metallurgy and Materials, vol. 16, no. 1, pp. 19-24, 2009.

[26] H. P. Xie, J. F. Liu, Y. Ju, J. Li, and L. Z. Xie, "Fractal property of spatial distribution of acoustic emissions during the failure process of bedded rock salt," International Journal of Rock Mechanics and Mining Sciences, vol. 48, no. 8, pp. 13441351, 2011.

[27] S. W. Zhang, K. Shou, X. Xian, J. Zhou, and G. Liu, "Fractal characteristics and acoustic emission of anisotropic shale in Brazilian tests," Tunnelling and Underground Space Technology, vol. 71, pp. 298-308, 2018.

[28] Y. Lou, Z. Wu, W. Sun et al., "Study on failure models and fractal characteristics of shale under seepage-stress coupling," Energy Science \& Engineering, vol. 8, no. 5, pp. 1634-1649, 2020.
[29] Y. Zhao, L. Zhang, J. Liao, W. Wang, Q. Liu, and L. Tang, "Experimental study of fracture toughness and subcritical crack growth of three rocks under different environments," International Journal of Geomechanics, vol. 20, no. 8, article 04020128, 2020.

[30] F. Sun, Y. Yao, G. Li, and W. Liu, "Simulation of real gas mixture transport through aqueous nanopores during the depressurization process considering stress sensitivity," Journal of Petroleum Science and Engineering, vol. 178, pp. 829-837, 2019.

[31] W. Zhang, Q. Sun, Y. Zhang, L. Xue, and F. Kong, "Porosity and wave velocity evolution of granite after high-temperature treatment: a review," Environmental Earth Sciences, vol. 77, no. 9, p. 350, 2018.

[32] Z. Baoyun, L. Dongyan, L. Ziyun, H. Wei, D. Qian, and L. Hang, "Mechanical behavior of shale rock under uniaxial cyclic loading and unloading condition," Advances in Civil Engineering, vol. 2018, 2018.

[33] J. Liu, W. Ding, R. Wang et al., "Quartz types in shale and their effect on geomechanical properties: an example from the lower Cambrian Niutitang Formation in the Cen'gong block, South China," Applied Clay Science, vol. 163, pp. 100-107, 2018.

[34] R. Wang, H. U. Zongquan, H. Nie et al., "Comparative analysis and discussion of shale reservoir characteristics in the Wufeng-Longmaxi and Niutitang formations: a case study of the well JY1 in SE Sichuan Basin and well TX1 in SE Guizhou area," Petroleum Geology \& Experiment, vol. 40, no. 5, 2018.

[35] Y. Zhao, Y. Wang, W. Wang, L. Tang, Q. Liu, and G. Cheng, "Modeling of rheological fracture behavior of rock cracks subjected to hydraulic pressure and far field stresses," Theoretical and Applied Fracture Mechanics, vol. 101, 2019.

[36] Y. Zhao, C. L. Wang, and J. Bi, “Analysis of fractured rock permeability evolution under unloading conditions by the model of elastoplastic contact between rough surfaces," Rock Mechanics and Rock Engineering, vol. 53, no. 12, pp. 57955808, 2020.

[37] Y. Zhao, L. Zhang, W. Wang, Q. Liu, L. Tang, and G. Cheng, "Experimental study on shear behavior and a revised shear strength model for infilled rock joints," International Journal of Geomechanics, vol. 20, no. 9, article 04020141, 2020.

[38] C. H. Wei, W. C. Zhu, Q. L. Yu, T. Xu, and S. Jeon, "Numerical simulation of excavation damaged zone under coupled thermal-mechanical conditions with varying mechanical parameters," International Journal of Rock Mechanics and Mining Sciences, vol. 75, pp. 169-181, 2015.

[39] F. Gao, Y. Xue, Y. Gao, Z. Zhang, T. Teng, and X. Liang, "Fully coupled thermo-hydro-mechanical model for extraction of coal seam gas with slotted boreholes," Journal of Natural Gas Science and Engineering, vol. 31, pp. 226-235, 2016.

[40] Q. L. Yu, C. Zheng, T. H. Yang, S. B. Tang, P. T. Wang, and C. A. Tang, "Meso-structure characterization based on coupled thermal-mechanical model for rock failure process and applications," Chinese Journal of Rock Mechanics and Engineering, vol. 31, no. 1, pp. 42-51, 2012.

[41] C. W. Zhu, C. H. Wei, J. Liu, H. Y. Qu, and D. Elsworth, "A model of coal-gas interaction under variable temperatures," International Journal of Coal Geology, vol. 86, no. 2-3, pp. 213-221, 2011.

[42] H. Xin, T. S. Bin, and T. C. An, "Boundary-effect and scaleheating rate equivalence effect of cracking behavior in the rock models subjected to heating from the central borehole," 
Science China Technological Sciences, vol. 63, no. 5, pp. 809818, 2020.

[43] C. A. Tang, H. Y. Liu, W. C. Zhu et al., "Numerical approach to particle breakage under different loading conditions," Powder Technology, vol. 143-144, pp. 130-143, 2004.

[44] Z. Wu, Y. Lou, S. Yin et al., "Acoustic and fractal analyses of the mechanical properties and fracture modes of beddingcontaining shale under different seepage pressures," Energy Science \& Engineering, vol. 8, no. 10, pp. 3638-3656, 2020. 